This is a postprint version of the following published document:

González-Rodríguez, S., [et al.] (2012). Potentiation of acute morphineinduced analgesia measured by a thermal test in bone cancer-bearing mice. Fundamental \& clinical pharmacology, vol. 26, no. 3, pp. 363-372. Avalaible in http://dx.doi.org/10.1111/j.1472-8206.2010.00921.x

(C) 2011 The Authors Fundamental and Clinical Pharmacology

C 2011 Société Française de Pharmacologie et de Thérapeutique 


\title{
Potentiation of acute morphine-induced analgesia measured by a thermal test in bone cancer-bearing mice
}

\author{
Sara González-Rodríguez ${ }^{\mathrm{a}}$, Sara Llames ${ }^{\mathrm{b}}$, Agustín Hidalgo ${ }^{\mathrm{a}}$, \\ Ana Baamonde ${ }^{\mathrm{a}}$, Luis Menéndez ${ }^{\mathrm{a} *}$ \\ ${ }^{\text {a }}$ Laboratorio de Farmacología, Facultad de Medicina, Instituto Universitario de Oncología del Principado de Asturias \\ (IUOPA), Universidad de Oviedo, C/ Julián Clavería 6, 33006 Oviedo, Asturias, Spain \\ Centro Comunitario de Sangre y Tejidos del Principado de Asturias, CIBER de Enfermedades Raras (CIBERER), U714, \\ Oviedo, Asturias, Spain \\ *Correspondence and reprints: luismen@uniovi.es
}

\begin{abstract}
Agonists of $\mu$-opioid receptors are currently used in the management of cancer pain. However, several data suggest that the analgesic effect of morphine can diminish during the development of experimental tumors. By using a thermal test, we have studied whether the analgesic effect evoked by morphine is altered in mice bearing two painful bone tumors. The analgesic effect evoked by systemic morphine remained unaltered after the intratibial inoculation of B16-F10 melanoma cells and was potentiated after the inoculation of NCTC 2472 osteosarcoma cells. Although the number of spinal $\mu$-opioid receptors measured by western blot studies was not augmented in osteosarcoma-bearing mice, the analgesia evoked by intrathecal (i.t.) morphine was also enhanced. The analgesic response produced by the spinal administration of the Gi/o protein activator mastoparan was amplified, whereas the analgesic response evoked by the i.t. administration of the N-type calcium channel blocker $\omega$-conotoxin remained unaltered. The efficacy of the GIRK channel blocker tertiapin- $Q$ to antagonize the analgesic effect produced by a maximal dose of morphine was also increased in osteosarcoma-bearing mice. Our results seem to indicate that the analgesic effect of morphine on thermal nociception can be enhanced in response to the development of particular bone tumors in mice, being this potentiation probably related to a greater efficacy of the transduction system driven by Gi/o proteins and GIRK channels.
\end{abstract}

\section{Keywords}

B16-F10, bone cancer, hot plate, mice, morphine, NCTC 2472

\section{INTRODUCTION}

The wide use of opiate drugs as analgesics is based on their good efficacy in different clinical settings. In particular, $\mu$-opioid receptor agonists are included in two of the three steps of the ladder for the control of chronic pain proposed by the WHO and are widely prescribed for the treatment of pain associated with cancer processes. It is well established that the analgesic effect induced by opioids can vary depending on the type of injury, as demonstrated both in humans and in laboratory animals. Thus, the analgesic effects induced by systemic morphine have been shown to be decreased in neuropathic states [1], while in animals bearing inflammatory processes they are generally enhanced [24]. Several mechanisms seem to be involved in the amplification of opiate analgesia during inflammation [3,5-7]. Among them, we have recently described that the increased analgesic effect of morphine measured by a thermal test in carrageenan-inflamed mice can be related to the amplification of the spinal effects triggered by Gi/o proteins and GIRK channels [8].

The inhibition of different behavioral nociceptive symptoms evoked by systemic morphine has been also 
studied in several bone cancer models. Thus, by using some variants of the painful tumor based on the intraosteal inoculation of NCTC 2472 fibrosarcoma cells, it was reported that systemic morphine reduces spontaneous flinches and guarding behavior $[9,10]$, thermal and mechanical hyperalgesia [10,11], or mechanical allodynia $[9,12,13]$ as well as normalizes the decreased grip force of the affected limbs [14], and similar data have been obtained in other models further developed by administering different tumoral cell types in mice and rats. The majority of the referred data indicate that the doses of morphine necessary to evoke acute analgesic effects in tumor-bearing rodents are rather high (10$50 \mathrm{mg} / \mathrm{kg}$ ) when compared to those active in other painful experimental situations or in healthy animals. However, some few reports describe the inhibition of particular neoplastic nociceptive symptoms by doses of morphine comparable to those useful to counteract pain symptoms linked to inflammatory processes. Thus, doses below $10 \mathrm{mg} / \mathrm{kg}$ reduce the spontaneous paw lifting and restore the use of the affected limb in mice inoculated with NCTC 2472 cells into the femur [10] and inhibit mechanical allodynia in tumor-bearing rats [15]. Finally, doses of morphine as low as $1-3 \mathrm{mg} / \mathrm{kg}$ are effective to counteract mechanical hyperalgesia in rats intratibially inoculated with different tumoral cells $[16,17]$.

During the past years, we have performed behavioral studies with two different models of murine bone cancer-induced pain, based on the intratibial inoculation of either fibrosarcoma NCTC 2472 cells, which evokes the growth of an osteoclastic tumor [11], or melanoma B16-F10 cells, which leads to the development of a mixed osteoclastic/osteoblastic bone tumor accompanied by an earlier instauration of hyperalgesia and allodynia [18]. In the present study, we explore whether changes in the analgesic effect evoked by systemic morphine occur in these two different murine neoplastic settings. We had previously described that the systemic administration of a high dose of morphine $(15 \mathrm{mg} / \mathrm{kg}$ ) completely prevented osteosarcoma-induced thermal hyperalgesia, increasing thermal withdrawal latencies of both hind paws up to cutoff values [11]. However, the range of active doses of morphine had not been described in this former paper and, related to mice inoculated with B16-F10 cells, the efficacy of systemic morphine has not been still explored. In this context, we study here whether differences in the analgesic potency of systemic morphine, assessed by measuring thermal latencies, appear in mice bearing each of the abovementioned bone tumors. Furthermore, as we detected that the analgesic effect of morphine is dramatically enhanced in one of these models, we have tried to elucidate whether some functional alterations in spinal Gi/o proteins and GIRK channels participate in the amplification morphine analgesia measured in these tumor-bearing mice, as previously described in carrageenan-inflamed mice [8].

\section{MATERIALS AND METHODS}

\section{Animals}

The experiments were performed in 5- to 6-week-old male $\mathrm{C} 3 \mathrm{H} / \mathrm{He}$ and $\mathrm{C} 57 \mathrm{BL} / 6$ mice bred in the Animalario de la Universidad de Oviedo (Reg. 33044 13A), maintained on a 12-h dark-light cycle with free access to food and water. Experimental procedures were approved by the Comité Ético de Experimentación Animal de la Universidad de Oviedo (Asturias, Spain). Each animal was used only once.

\section{Drugs and drug administration}

Morphine hydrochloride (Ministerio de Sanidad, Madrid, Spain), the $\mathrm{G}_{\mathrm{i} / \mathrm{o}}$ protein activator mastoparan (Tocris), the N-type $\mathrm{Ca}^{2+}$ channel blocker $\omega$-conotoxin GVIA (Tocris), and the GIRK channel blocker tertiapin-Q (Tocris) were used. Drugs were dissolved in saline.

For intrathecal (i.t.) injections, a slight modification of the original method [19] was used. Briefly, a lumbar cut was made, and the tip of a 30-gauge needle inserted in a Hamilton microsyringe was introduced at the level of $\mathrm{L}_{5}-\mathrm{L}_{6}$ to inject a volume of $5 \mu \mathrm{L}[8]$.

\section{Cell inoculation}

NCTC 2472 osteosarcoma cells and B16-F10 melanoma cells (ATCC) were cultured and passaged weekly as previously described $[11,18]$. Cells were detached by scraping and centrifuged, and the remaining pellet suspended in PBS. For surgical procedures, anesthesia was induced by spontaneous inhalation of $3 \%$ isoflurane (Isoflo ${ }^{\circledR}$; Esteve, Barcelona, Spain) and maintained by administering $1.5 \%$ isoflurane in oxygen through a breathing mask. A suspension of $10^{5}$ cells in $5 \mu \mathrm{L}$ of PBS was injected into the right tibial medullar cavity and, after applying acrylic glue (Hystoacril ${ }^{\circledR}$; Braun, Barcelona, Spain) on the tibial plateau incised area, surgery was finished with a stitch of the skin. Control mice were inoculated with $10^{5}$ cells killed by quickly freezing them three times without cryoprotection. Thermal hyperalgesia was studied 4 weeks after the inoculation of NCTC 2472 cells [11] and 1 week after B16-F10 cell inoculation [18]. 


\section{Unilateral hot plate}

Mice were gently restrained, and the plantar side of the tested paw was placed on the hot plate surface $\left(52.5 \pm 1{ }^{\circ} \mathrm{C}\right)$ [20]. Measurements of withdrawal latencies from the heated surface of each hind paw were made separately at 2-min intervals, and the mean of two measures was considered. A cutoff of $30 \mathrm{~s}$ was established. Experiments were performed between 15:00 and 20:00 in a thermostatized $\left(2{ }^{\circ} \mathrm{C}\right)$ and noise-isolated room.

\section{Western blot assays}

Four weeks after NCTC 2472 cell inoculation, mice were exposed to $\mathrm{CO}_{2}$ and decapitated. Lumbar spinal cord was extracted by flushing 1-2 mL of ice-cold saline through the spinal cavity with a syringe, and L2-L6 lumbar spinal segments were conserved at $-80^{\circ} \mathrm{C}$. Each sample came from a unique animal.

As previously described [8], spinal cords were homogenized and the supernatant obtained after centrifugation $\left(26000 \mathrm{~g}, 20 \mathrm{~min}, 4{ }^{\circ} \mathrm{C}\right)$ was collected. Protein concentrations were determined by a BCA protein assay (Pierce, Rockford, IL, USA). Samples (100 $\mu \mathrm{g}$ of protein in $30 \mu \mathrm{L}$ of buffer) were run on a 10\% SDS-PAGE gel at $90 \mathrm{~V}$ and then transferred onto nitrocellulose (Bio-Rad, Hercules, CA, USA) at $4{ }^{\circ} \mathrm{C}$ during $90 \mathrm{~min}$ at $100 \mathrm{~V}$. The nitrocellulose membrane was blocked in Tris-buffered saline-Tween with 5\% non-fat milk for $90 \mathrm{~min}$ at RT, washed, and incubated overnight at $4{ }^{\circ} \mathrm{C}$ with rabbit polyclonal anti- $\mu$-opioid receptor ( 1 : 2000; Chemicon, Billerica, MA, USA). After incubation, the membrane was washed and incubated with the secondary antibody (anti-rabbit Ig G, 1 : 14000; Sigma) in the presence of $0.1 \%$ non-fat milk for $90 \mathrm{~min}$. Labeled $\mu$-opioid receptor protein was detected by enhanced chemiluminescence detection autoradiography using Supersignal West Pico Chemiluminiscent Substrate kit (Pierce). Immune reaction intensity was determined by computer-assisted densitometry (ImageJ, NIH, Bethesda, MD, USA).

Glyceraldehyde-3-phosphate dehydrogenase (GAPDH), a constitutively expressed protein of $35 \mathrm{kDa}$, was also measured using a polyclonal rabbit anti-mouse GAPDH antibody (1 : 30000; Sigma, St. Louis, MO, USA). Results are reported as the ratio of optical densities of $\mu$-opioid receptor and GAPDH by normalizing the amount of $\mu$-opioid receptor to the immunoreactivity of GAPDH.

\section{Statistical analysis}

Mean values and their corresponding standard errors were calculated. Intergroup comparisons in the doseeffect curves were made by an initial one-way analysis of variance followed by the Dunnett's $t$ test. Comparisons of western blot data were made by the Student's $t$-test.

$\mathrm{ED}_{50}$ values were calculated by constructing quantal dose-effect curves with the computer program Pharm Tools Pro (version 1.27; The McCary Group Inc., Schnecksville, PA, USA). This parameter represents the dose that yields analgesia in $50 \%$ of mice. A latency value was considered to be analgesic when it surpassed the $50 \%$ of the maximal analgesic effect. The $50 \%$ of the maximal analgesic effect was calculated considering the latency value obtained in the left paw of each group of mice in basal conditions and the cutoff established in $30 \mathrm{~s}$. Thus, in a prototypical case in which basal latencies in non-inflamed paws is $14 \mathrm{~s}$, the latency corresponding to the $50 \%$ of maximal analgesic effect should be 22 s. Comparisons between $\mathrm{ED}_{50}$ values were made by an ANOVA. In all cases, statistical significance was considered at $P<0.05$.

\section{RESULTS}

Increase in thermal withdrawal latencies evoked by systemic morphine in mice intratibially inoculated with NCTC 2472 or B16-F10 cells

In mice inoculated with killed cells, withdrawal latencies of both hind paws were measured. However, as values obtained in both paws were almost identical, only those corresponding to their right paws were analyzed in all experiments.

The s.c. administration of morphine to $\mathrm{C} 3 \mathrm{H} / \mathrm{He}$ mice inoculated with killed NCTC 2472 cells produced dosedependent analgesia, being $1.7 \mathrm{mg} / \mathrm{kg}$ the lowest dose assayed able to significantly increase withdrawal latencies and $5 \mathrm{mg} / \mathrm{kg}$ the one producing the maximal analgesic response (Figure 1a). The calculated $\mathrm{ED}_{50}$ in the right paw was $2.75 \pm 0.17 \mathrm{mg} / \mathrm{kg}$.

Thermal hyperalgesia detected in the affected (right) hind paw of mice inoculated with live NCTC 2472 cells was inhibited by the s.c. injection of doses of morphine as low as $0.1 \mathrm{mg} / \mathrm{kg}$. Remarkably, doses higher than $0.1 \mathrm{mg} / \mathrm{kg}$ produced an enhanced analgesic effect compared with that obtained in mice inoculated with killed cells not only in the injured one but in both hind paws. Maximal analgesia was observed after the administration of $1 \mathrm{mg} / \mathrm{kg}$ of morphine (Figure $1 \mathrm{~b}$ ). The calculated $\mathrm{ED}_{50}$ was $0.492 \pm 0.11 \mathrm{mg} / \mathrm{kg}$ in the left paw and $0.495 \pm$ $0.124 \mathrm{mg} / \mathrm{kg}$ in the right one.

The potency of morphine in C57BL/ 6 mice inoculated with killed B16-F10 cells (Figure 1c) was similar to 
(a)

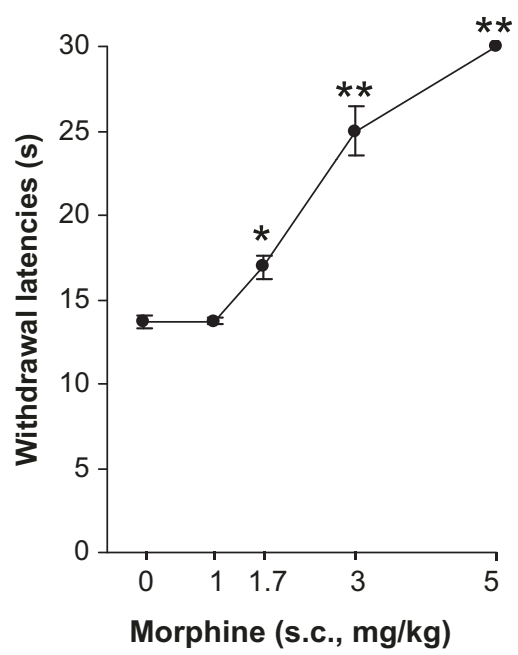

(c) Killed B16-F10 cells

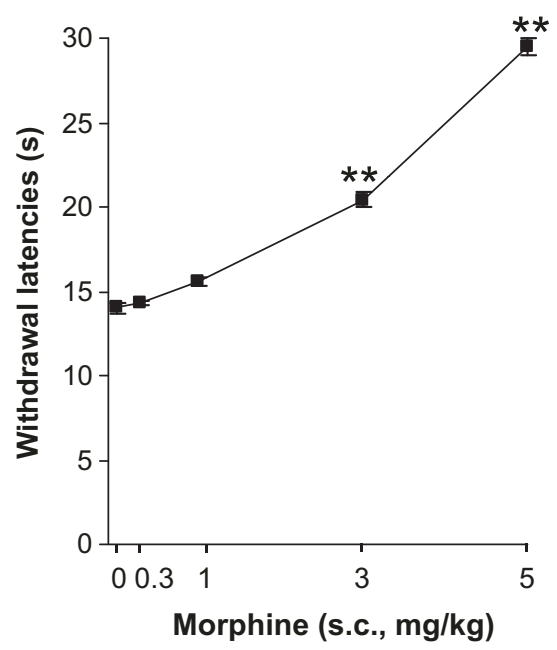

(b)

\section{Live NCTC 2472 cells}

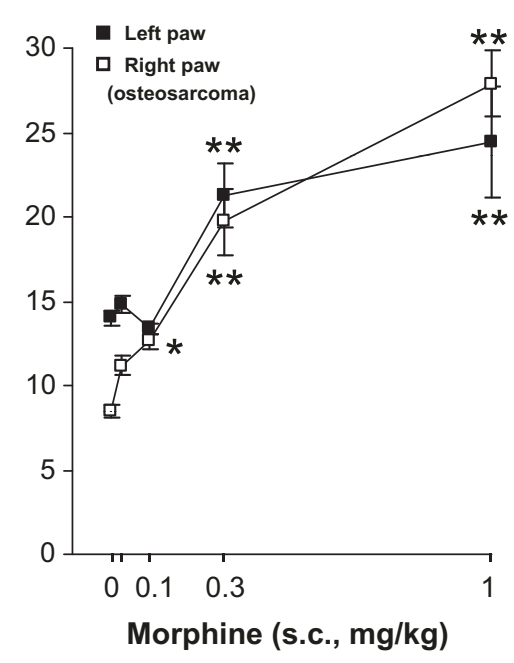

(d) Live B16-F10 cells

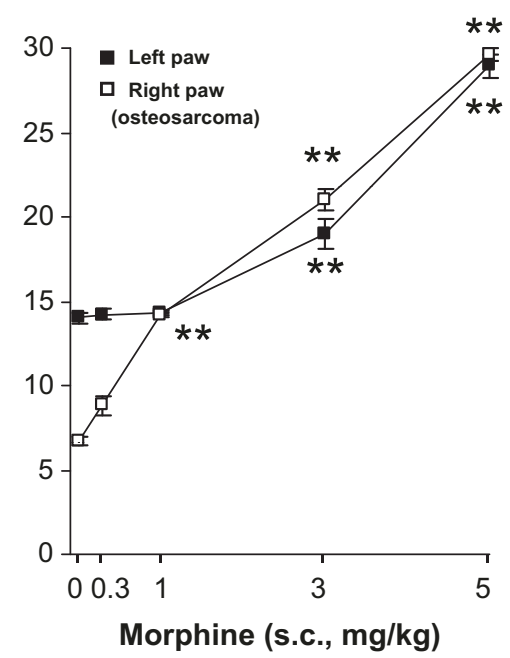

Figure 1 Analgesic effect induced by systemic morphine in mice inoculated in their right tibiae with killed (a) or live (b) NCTC 2472 cells or killed (c) or live (d) B16-F10 cells. Each point represents the mean withdrawal latency value with its corresponding standard error $(n=5-7)$. ${ }^{*} P<0.05,{ }^{* *} P<0.01$, compared with saline-treated mice of each group, Dunnett's $t$ test. that observed in $\mathrm{C} 3 \mathrm{H} / \mathrm{He}$ mice. Thus, analgesic responses appeared at doses higher than $1 \mathrm{mg} / \mathrm{kg}$, being the maximal effect attained after the administration of $5 \mathrm{mg} / \mathrm{kg}$ of morphine and leading to an $\mathrm{ED}_{50}$ value of $2.44 \pm 0.72 \mathrm{mg} / \mathrm{kg}$. As represented in Figure $1 d$, when morphine was administered to C57BL/ 6 mice inoculated with live B16-F10 cells, no modification of the potency of morphine to evoke analgesic effects was observed although an antihyperalgesic effect after the administration of $1 \mathrm{mg} / \mathrm{kg}$ of morphine was detected. The calculated $\mathrm{ED}_{50}$ values were $3.7 \pm 1.96$ and $2.4 \pm 0.98 \mathrm{mg} / \mathrm{kg}$ for the left and right paws, respectively.
Increase in thermal withdrawal latencies evoked by intrathecal morphine in mice intratibially inoculated with NCTC 2472 cells

To elucidate whether osteosarcoma development enhances the analgesic effects produced by morphine at the spinal cord, dose-response curves were constructed after the i.t. administration of morphine to $\mathrm{C} 3 \mathrm{H} / \mathrm{He}$ mice inoculated with either killed or live NCTC 2472 cells. The i.t. administration of $0.5 \mu \mathrm{g}$ of morphine produced a significant increase in thermal withdrawal latencies of mice inoculated with killed cells, being the maximal analgesia reached after administering $1 \mu \mathrm{g}$ of morphine (Figure $2 a$ ). The $\mathrm{ED}_{50}$ was $0.529 \pm 0.036 \mu \mathrm{g}$. In con- 
(a)

Killed NCTC 2472 cells

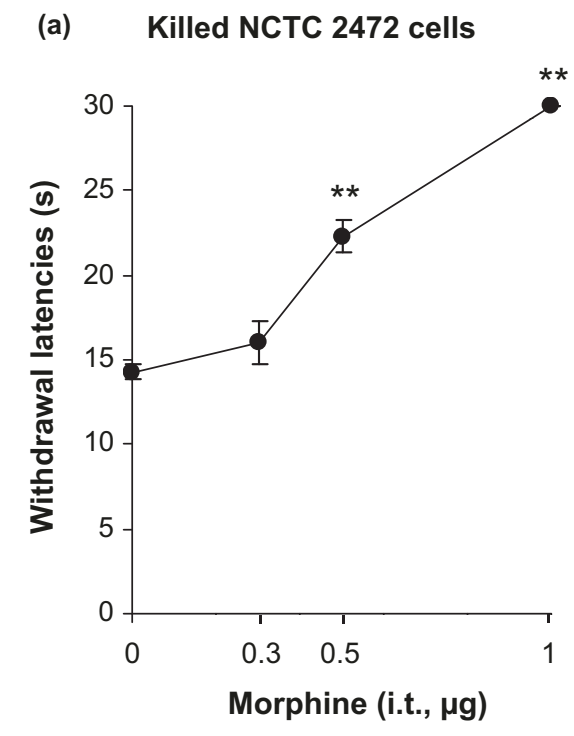

nett's $t$ test.

Figure 2 Analgesic effect induced by i.t. morphine in $\mathrm{C} 3 \mathrm{H} / \mathrm{He}$ mice inoculated in their right tibiae with killed (a) or live (b) NCTC 2472 cells. Each point represents the mean withdrawal latency value with its corresponding standard error $(n=6)$. ${ }^{*} P<0.05,{ }^{* *} P<0.01$, compared with saline-treated mice of each group, Dunnett's t test. (b) Live NCTC 2472 cells

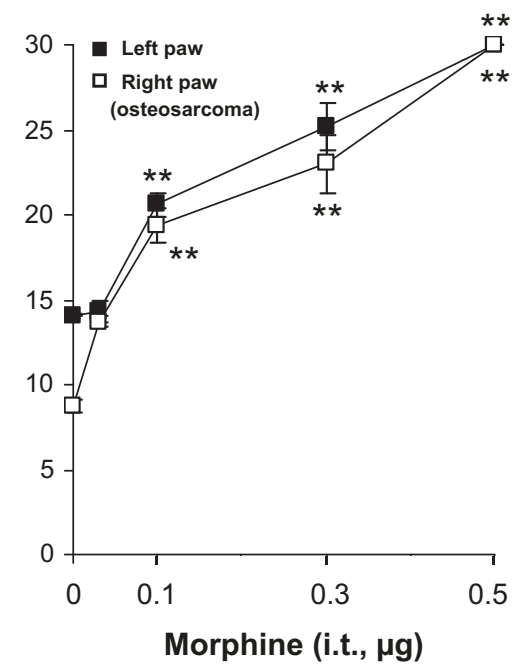

(b) $\square$ Killed NCTC 2472

(a) Killed Live
NCTC NCTC as low as $0.1 \mu \mathrm{g}$ evoked a consistent effect and $0.5 \mu \mathrm{g}$ provoked maximal analgesia, leading to $\mathrm{ED}_{50}$ values of $0.16 \pm 0.036 \mu \mathrm{g}$ in the left paw and $0.19 \pm 0.099 \mu \mathrm{g}$ in the right one (Figure $2 b$ ).

\section{Measurement by western blot of spinal $\mu$-opioid receptors expressed in mice inoculated with NCTC 2472 cells}

Western blot experiments were performed in lumbar spinal cord tissue from mice intratibially inoculated with either killed or live NCTC 2472 cells. A band of $45 \mathrm{kDa}$, compatible with the $\mu$-opioid receptors, was detected in both cases (Figure 3a), although no difference in the ratios of the $\mu$-opiod receptor and GAPDH expression was found between mice inoculated with killed or live NCTC 2472 cells (Figure 3b).

Effects of the i.t. administration of the Gi/o protein activator mastoparan on thermal withdrawal latencies of mice inoculated with NCTC 2472 cells

The i.t. administration of $3 \mu \mathrm{g}$ of mastoparan to mice inoculated with killed NCTC 2472 cells produced a significant analgesic effect that was maximal when $5 \mu \mathrm{g}$ was administered (Figure $4 a$ ). The calculated $\mathrm{ED}_{50}$ was $2.56 \pm 0.75 \mu \mathrm{g}$.

An antihyperalgesic effect at low doses of mastoparan and a potentiation of the analgesic effect of higher ones were detected in osteosarcoma-bearing mice. Thus, significant analgesia was induced in both paws after the administration of $1 \mu \mathrm{g}$, and maximal analgesia was
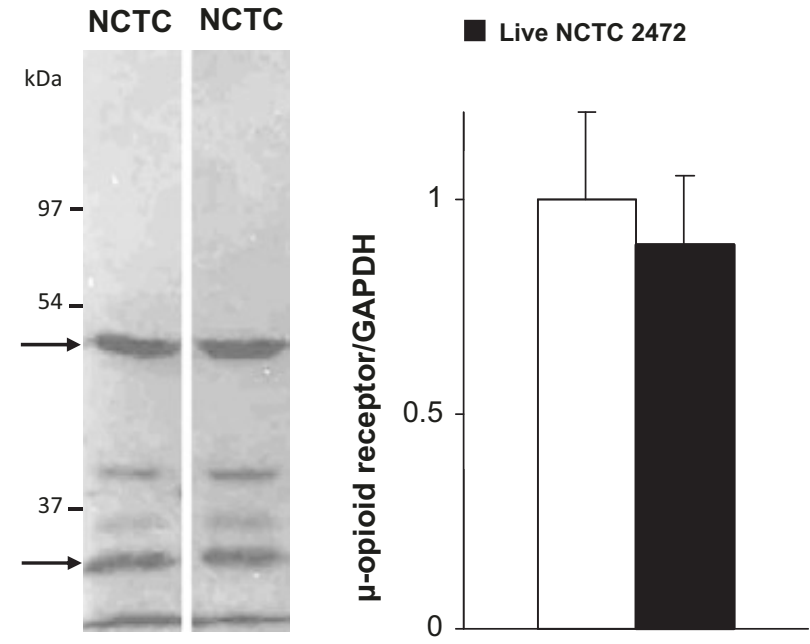

Figure 3 Expression of $\mu$-opioid receptors measured by western blot in lumbar spinal cord segments of $\mathrm{C} 3 \mathrm{H} / \mathrm{He}$ mice intratibially inoculated with NCTC 2472 cells. (a) Representative lanes of western blot experiments performed in mice inoculated with killed (left panel) or live (right panel) NCTC 2472 cells. Molecular weight markers are indicated at the left side, and bands corresponding to $\mu$-opioid receptor protein (at $45 \mathrm{kDa}$ approximately) and GAPDH (at $35 \mathrm{kDa}$ approximately) are signaled with an arrow. (b) Fold change in $\mu$-opioid receptors protein estimated by using its corresponding GAPDH as endogenous control in lumbar spinal cords of mice inoculated with either killed or live cells. Data are the mean $\pm \operatorname{SEM}(n=5)$.

attained after the administration of $3 \mu \mathrm{g}$ (Figure $4 b$ ). The calculated $\mathrm{ED}_{50}$ were $0.783 \pm 0.277$ and $0.98 \pm 0.116$ $\mu \mathrm{g}$ in the left and right paws. 
(a) Killed NCTC 2472 cells

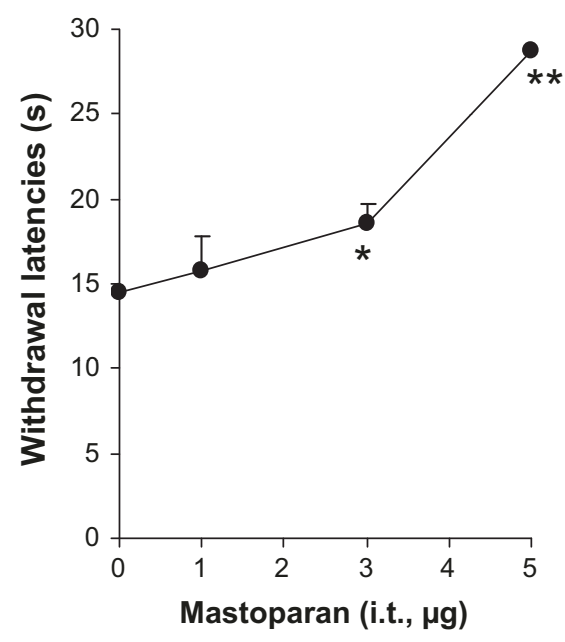

(b) Live NCTC 2472 cells

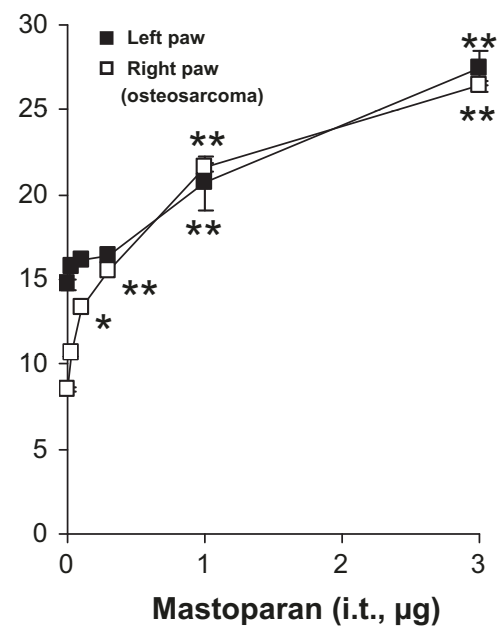

Figure 4 Analgesic effect induced by i.t. administration of mastoparan in $\mathrm{C} 3 \mathrm{H} / \mathrm{He}$ mice inoculated in their right tibiae with killed (a) or live (b) NCTC 2472 cells. Each point represents the mean withdrawal latency value with its corresponding standard error $(n=6)$. ${ }^{*} P<0.05,{ }^{* *} P<0.01$, compared with saline-treated mice of each group, Dunnett's $t$ test.
Effects of the i.t. administration of $\omega$-conotoxin GVIA on thermal withdrawal latencies of mice inoculated with NCTC 2472 cells

The spinal administration of $\omega$-conotoxin GVIA produced dose-dependent analgesia in mice inoculated with killed cells, leading to an $\mathrm{ED}_{50}$ of $1.84 \pm 0.165 \mathrm{ng}$ (Figure 5a).

In osteosarcoma-bearing mice, lower doses of this drug produced an antihyperalgesic effect in the injured paw (Figure 5b). However, the ability of this drug to increase withdrawal latencies above basal latency values was not enhanced. $\mathrm{ED}_{50}$ values obtained in both paws of mice inoculated with live NCTC 2472 cells were $2.225 \pm 0.98 \mathrm{ng}$ in the left paw and $3.23 \pm 0.43 \mathrm{ng}$ in the right one.
Effects of the i.t. coadministration of the GIRK inhibitor tertiapin-Q on the enhanced analgesia evoked by i.t. morphine in mice inoculated with NCTC 2472 cells

In mice inoculated with killed NCTC 2472 cells, the i.t. coadministration of tertiapin-Q (75-250 ng) evoked a dose-dependent inhibition of the maximal analgesia evoked after the administration of $1 \mu \mathrm{g}$ of i.t. morphine (Figure 6a). The calculated $\mathrm{ED}_{50}$ value was $108 \pm$ $13.3 \mathrm{ng}$.

The coadministration of tertiapin also reduced the maximal analgesia evoked by the administration of $0.5 \mu \mathrm{g}$ of morphine in mice inoculated with live NCTC 2472 cells (Figure 6b). A complete reversion occurred (a)

Killed NCTC 2472 cells

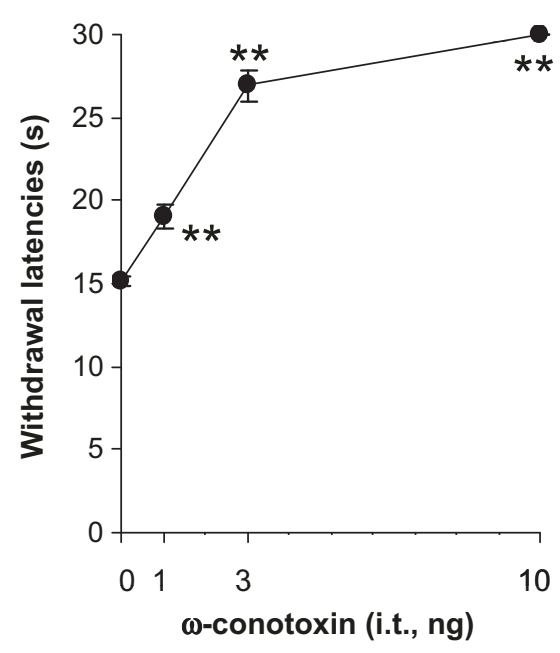

(b) Live NCTC 2472 cells

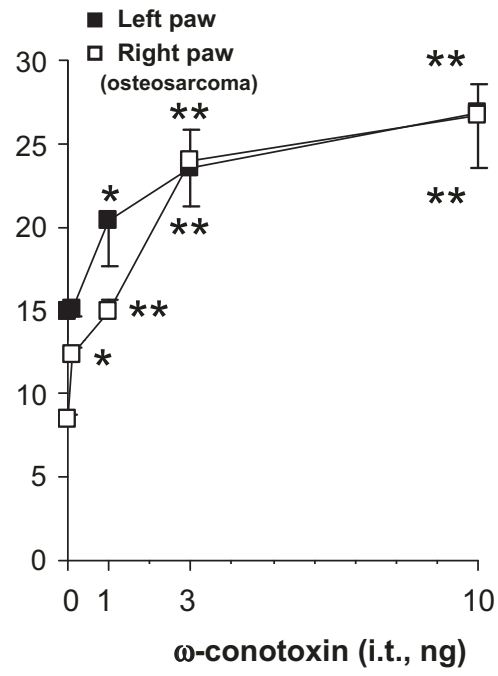

Figure 5 Analgesic effect induced by i.t. administration of $\omega$-conotoxin in $\mathrm{C} 3 \mathrm{H} /$ $\mathrm{He}$ mice inoculated in their right tibiae with killed (a) or live (b) NCTC 2472 cells. Each point represents the mean withdrawal latency value with its corresponding standard error $(n=6)$. ${ }^{*} P<0.05,{ }^{* *} P<0.01$, compared with saline-treated mice of each group, Dunnett's $t$ test. 
(a) Killed NCTC 2472 cells

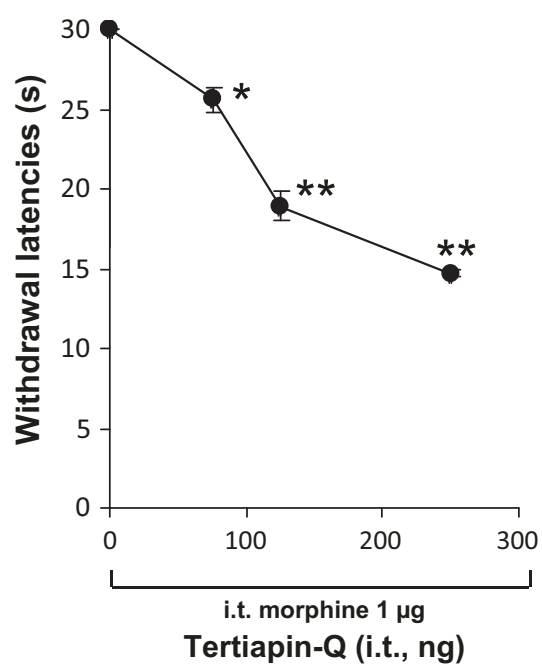

(b) Live NCTC 2472 cells

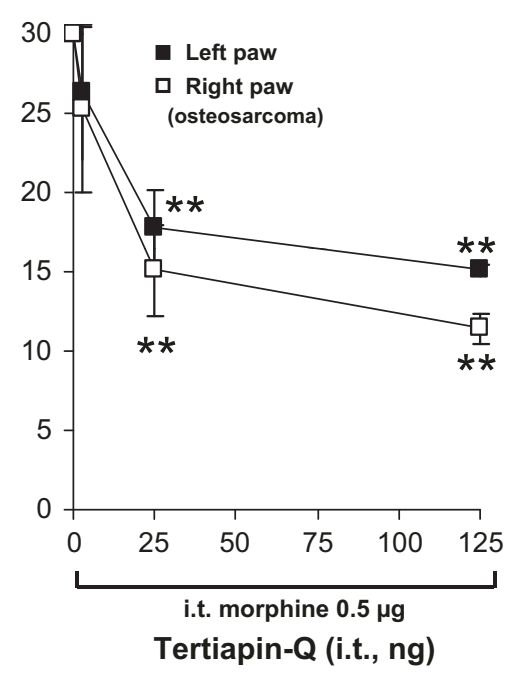

Figure 6 Effects of i.t. coadministration of tertiapin- $Q$ on the analgesic effect produced by morphine in C3H/He mice inoculated in their right tibiae with NCTC 2472 cells. (a) Inhibitory effect of tertiapin- $Q$ on the analgesic effect induced by $1 \mu \mathrm{g}$ of morphine in the right hind paws of mice inoculated with killed NCTC 2472 cells. (b) Inhibitory effect of tertiapin- $Q$ on the analgesic effect induced by $0.5 \mu \mathrm{g}$ of morphine measured in the left and the right paws of mice inoculated with live NCTC 2472 cells. Each point represents the mean withdrawal latency value with its corresponding standard error $(n=6)$. ${ }^{*} P<0.05$, ${ }^{* *} P<0.01$, compared with morphine-treated mice of each group, Dunnett's $t$ test.

after the administration of $125 \mathrm{ng}$ of tertiapin and $\mathrm{ED}_{50}$ values of $8.2 \pm 3.5$ and $6.1 \pm 3.77 \mathrm{ng}$ were obtained in the left and the right paw, respectively.

\section{DISCUSSION}

We show here, using a thermal test, that the effect of systemic morphine in mice inoculated with B16-F10 cells is similar to that measured in mice without tumor and that, strikingly, the effect of morphine is strongly potentiated in mice inoculated with NCTC 2472 osteosarcoma cells.

The inhibitory effect of systemic morphine on thermal nociceptive reactions has been previously studied in tumor-bearing mice after its acute administration [11] or continuous perfusion [21]. Here, we have tested its effects either 1 week after the inoculation of B16-F10 cells or 4 weeks after intratibial administration of NCTC 2472 cells, the corresponding times at which thermal hyperalgesia can be detected in each case, as previously described $[11,18]$. Our results show that morphine induces analgesic responses in $\mathrm{C} 57 \mathrm{BL} / 6$ mice receiving the intratibial inoculation of B16-F10 melanoma cells at doses similar to those effective in mice inoculated with killed cells, being the potency of morphine indistinguishable in both cases. The result obtained in osteosarcoma- bearing mice was surprising, because the doses of morphine necessary to increase thermal withdrawal latencies in both paws were significantly lower than those effective in mice inoculated with killed cells. As commented in the introduction, the information available indicated that the analgesic efficacy of morphine is usually reduced in mice bearing neoplastic processes. An obvious consideration to explain this discrepancy is the influence of the method used to measure nociception. Thus, whereas thermal or mechanical withdrawal latencies can be augmented by the activation of peripheral opioid receptors in tumor-bearing mice, the response to the stimulation with von Frey filaments remains unaltered [18]. It seems then necessary to assume that the present result cannot be generalized to other nociceptive parameters. As we have previously described the involvement of spinal mechanisms in the potentiation of the analgesic effects induced by morphine in the same thermal test in carrageenan-inflamed mice [8], we tried to elucidate whether these mechanisms are also implicated in the potentiation of morphine measured in osteosarcoma-bearing mice.

In particular, the amplification of morphine-induced analgesia observed in carrageenan-inflamed mice was related to the stimulation of spinal opioid receptors, independent on their upregulation, and mediated by the 
amplification of Gi/o-GIRK transductional mechanisms in the spinal cord [8]. The present experiments indicate that these mechanisms also participate in the enhanced effect of morphine measured in osteosarcoma-bearing mice. Thus, the analgesic effect induced by morphine at spinal level is also enhanced in mice inoculated with NCTC 2472 cells, as demonstrated after its intrathecal administration and, although a slight reduction in this population of receptors has been previously found in mice receiving the intrafemoral inoculation of NCTC 2472 cells [22], no change was found in the expression of $\mu$-opioid receptors at the spinal level in our western blot experiments.

The analgesia evoked by the spinal administration of the Gi/o protein activator mastoparan [23] was also potentiated in osteosarcoma-bearing mice although less markedly than in inflamed mice [8]. Because analgesia is attained after the administration of lower doses of mastoparan in osteosarcoma-bearing mice than in control ones, it may be conceived that the activation of less $\mathrm{Gi} / \mathrm{o}$ proteins is necessary to evoke analgesia in osteosarcoma-bearing mice, as previously proposed in inflamed mice [8]. In addition, the description that mastoparan induces analgesic responses in cancer-bearing mice suggests that the activation of $\mathrm{Gi} / \mathrm{o}$ proteins could perhaps represent a theoretical strategy to counteract some painful symptoms related to these settings.

Considering that the analgesic effects of morphine at the spinal cord can be mediated by opioid receptors located at presynaptic or postsynaptic level, we have tested whether the functionality of some of the main targets modulated by morphine at presynaptic level, such as N-type calcium channels [24], or postsynaptically, such as G-coupled inwardly rectifying potassium channels (GIRK) [25,26], would be altered in mice bearing the osteosarcoma. The analgesic effect produced after the spinal administration of the N-type calcium channels blocker $\omega$-conotoxin GVIA was not potentiated in mice inoculated with NCTC 2472 cells, thus suggesting that an enhanced efficacy of these channels does not participate in this potentiation. Related to spinal postsynaptic mechanisms, it has been shown that the analgesic effects induced by intrathecally administered morphine is importantly linked to the activation of GIRK channels [25] which are almost exclusively expressed at postsynaptic level in the spinal cord [26]. The spinal administration of morphine together with tertiapin-Q, a GIRK channel blocker, dose-dependently inhibited the analgesic effect induced by the opioid receptor agonist, being necessary smaller doses of tertiapin- $Q$ to avoid the effect of morphine in osteosarcoma-bearing mice. Thus, it could be thought that the activation of a lower number of GIRK channels is enough to evoke analgesia in osteosarcoma-bearing mice, suggesting an increased efficacy of these channels. Because a relationship has been established between the activation of NMDA receptors and an increased presence of GIRK2 channels in the cell surface of cultured hippocampal neurons [27], it could be speculated that a change in GIRK efficacy could follow the activation of spinal NMDA receptors, which has been previously demonstrated in osteosarcoma-bearing mice [28]. However, it does not seem easy to explain why this mechanism does not participate in the bone cancer model owing to the inoculation of melanoma cells in which NMDA receptors probably play a role. The scarce information related to the spinal alterations owing to the intraosteal inoculation of B16F10 cells makes difficult to speculate about the reasons underlying the different results produced by morphine in both tumoral models. It has been previously described that the expression of some spinal markers of pain such as c-Fos or dynorphin is similar after intrafemoral NCTC 2472 or B16-F10 cell inoculation in immunodeficient mice, whereas a marked difference appears in the intensity of spinal astrogliosis, significantly greater in the osteosarcoma model [29]. In any case, a hypothetical link between increased astrogliosis and the enhancement of morphine effects seems unlikely because, indeed, glial activity is related to the diminution of opioid analgesia [30]. Thus, additional data seem necessary to offer a more comprehensive explanation for the different potency of morphine in mice inoculated with NCTC 2472 or B16-F10 cells.

In conclusion, our data indicate that the analgesic effect evoked by morphine on thermal nociception can be enhanced in particular types of experimental bone tumors, such as that produced by the intraosteal inoculation of NCTC 2472 cells, remaining unmodified after the inoculation of B16-F10 cells. Because these data related to thermal analgesia suggest that some transductional mechanisms can be altered in the sense of potentiation, the idea that morphine is less efficacious in experimental bone cancer models does not seem a general rule. The spinal mechanisms involved in the potentiation of morphine in the osteosarcoma are rather similar to those previously described after acute inflammation. Thus, although a lesser potentiation of the Gi/ o-protein-mediated analgesic effect triggered by mastoparan appeared in NCTC 2472 inoculated mice, the increased efficacy of spinal postsynaptic GIRK channels 
and not presynaptic calcium channels seems implicated in the potentiation of morphine-induced analgesia in both experimental situations.

\section{ACKNOWLEDGEMENTS}

Grants were provided by MEC-FEDER (SAF2009-10567). SL received a grant from CIBER of Enfermedades Raras of the Instituto de Salud Carlos III (ISCIII).The Instituto Universitario de Oncología is supported by Obra Social Cajastur-Asturias, Spain.

\section{REFERENCES}

1 Przewlocki R., Przewlocka B. Opioids in neuropathic pain. Curr. Pharm. Des. (2005) 11 3013-3025.

2 Przewłocki R., Przewłocka B. Opioids in chronic pain. Eur. J. Pharmacol. (2001) 429 79-91.

3 Perrot S., Guilbaud G., Kayser V. Differential behavioral effects of peripheral and systemic morphine and naloxone in a rat model of repeated acute inflammation. Anesthesiology (2001) 94 870-875.

4 Sykes K.T., White S.R., Hurley R.W., Mizoguchi H., Tseng L.F., Hammond D.L. Mechanisms responsible for the enhanced antinociceptive effects of micro-opioid receptor agonists in the rostral ventromedial medulla of male rats with persistent inflammatory pain. J. Pharmacol. Exp. Ther. (2007) 322 813821.

5 Przewłocka B., Dziedzicka M., Lason' W., Przewłocki R. Differential effects of opioid receptor agonists on nociception and cAMP level in the spinal cord of monoarthritic rats. Life Sci. (1992) 50 45-54.

6 Stanfa L.C., Dickenson A.H. Cholecystokinin as a factor in the enhanced potency of spinal morphine following carrageenin inflammation. Br. J. Pharmacol. (1993) 108 967-973.

7 Yang H.Y., Tao T., Iadarola M.J. Modulatory role of neuropeptide FF system in nociception and opiate analgesia. Neuropeptides (2008) 42 1-18.

8 González-Rodríguez S., Hidalgo A., Baamonde A., Menéndez L. Involvement of Gi/o proteins and GIRK channels in the potentiation of morphine-induced spinal analgesia in acutely inflamed mice. Naunyn Schmiedebergs Arch. Pharmacol. (2010) 381 59-71.

9 Luger N.M., Sabino M.A., Schwei M.J. et al. Efficacy of systemic morphine suggests a fundamental difference in the mechanisms that generate bone cancer vs inflammatory pain. Pain (2002) 99 397-406.

10 Mouedden M.E., Meert T.F. Pharmacological evaluation of opioid and non-opioid analgesics in a murine bone cancer model of pain. Pharmacol. Biochem. Behav. (2007) 86 458467.

11 Menéndez L., Lastra A., Fresno M.F. et al. Initial thermal heat hypoalgesia and delayed hyperalgesia in a murine model of bone cancer pain. Brain Res. (2003) 18 102-109.
12 Honore P., Rogers S.D., Schwei M.J. et al. Murine models of inflammatory, neuropathic and cancer pain each generates a unique set of neurochemical changes in the spinal cord and sensory neurons. Neuroscience (2000) 98 585-598.

13 Minami K., Hasegawa M., Ito H. et al. Morphine, oxycodone, and fentanyl exhibit different analgesic profiles in mouse pain models. J. Pharmacol. Sci. (2009) 111 60-72.

14 Wacnik P.W., Kehl L.J., Trempe T.M., Ramnaraine M.L., Beitz A.J., Wilcox G.L. Tumor implantation in mouse humerus evokes movement-related hyperalgesia exceeding that evoked by intramuscular carrageenan. Pain (2003) 101 175-186.

15 Beyreuther B.K., Callizot N., Brot M.D., Feldman R., Bain S.C., Stöhr T. Antinociceptive efficacy of lacosamide in rat models for tumor- and chemotherapy-induced cancer pain. Eur. J. Pharmacol. (2007) 22 98-104.

16 Medhurst S.J., Walker K., Bowes M. et al. A rat model of bone cancer pain. Pain (2002) 96 129-140.

17 Urch C.E., Donovan-Rodriguez T., Gordon-Williams R., Bee L.A., Dickenson A.H. Efficacy of chronic morphine in a rat model of cancer-induced bone pain: behaviour and in dorsal horn pathophysiology. J. Pain (2005) 6 837-845.

18 Curto-Reyes V., Juárez L., García-Pérez E. et al. Local loperamide inhibits thermal hyperalgesia but not mechanical allodynia induced by intratibial inoculation of melanoma cells in mice. Cell. Mol. Neurobiol. (2008) 28 981-990.

19 Hylden J.L., Wilcox G.L. Intrathecal morphine in mice: a new technique. Eur. J. Pharmacol. (1980) 17 313-316.

20 Menéndez L., Lastra A., Hidalgo A., Baamonde A. Unilateral hot plate test: a simple and sensitive method for detecting central and peripheral hyperalgesia in mice. J. Neurosci. Meth. (2002) 113 91-97.

21 King T., Vardanyan A., Majuta L. et al. Morphine treatment accelerates sarcoma-induced bone pain, bone loss, and spontaneous fracture in a murine model of bone cancer. Pain (2007) $132154-168$.

22 Yamamoto J., Kawamata T., Niiyama Y., Omote K., Namiki A. Down-regulation of mu opioid receptor expression within distinct subpopulations of dorsal root ganglion neurons in a murine model of bone cancer pain. Neuroscience (2008) 151 843-853.

23 Odagaki Y., Nishi N., Koyama T. Receptor-mediated and receptor-independent activation of G-proteins in rat brain membranes. Life Sci. (1998) 62 1537-1541.

24 Moises H.C., Rusin K.I., Macdonald R.L. mu-Opioid receptormediated reduction of neuronal calcium current occurs via a G (o)-type GTP-binding protein. J. Neurosci. (1994) $143842-$ 3851.

25 Marker C.L., Stoffel M., Wickman K. Spinal G-protein-gated K+ channels formed by GIRK1 and GIRK2 subunits modulate thermal nociception and contribute to morphine analgesia. J. Neurosci. (2004) 24 2806-2812.

26 Marker C.L., Luján R., Loh H.H., Wickman K. Spinal G-proteingated potassium channels contribute in a 
dose-dependent manner to the analgesic effect of mu- and deltabut not kappa-opioids. J. Neurosci. (2005) 25 3551-3559.

27 Chung H.J., Qian X., Ehlers M., Jan Y.N., Jan L.Y. Neuronal activity regulates phosphorylation-dependent surface delivery of $\mathrm{G}$ protein-activated inwardly rectifying potassium channels. Proc. Natl. Acad. Sci. (2009) 106 629-634.

$28 \mathrm{Gu}$ X., Zhang J., Ma Z. et al. The role of N-methyl-D-aspartate receptor subunit NR2B in spinal cord in cancer pain. Eur. J. Pain (2010) 14 496-502.
29 Sabino M.A., Luger N.M., Mach D.B., Rogers S.D., Schwei M.J., Mantyh P.W. Different tumors in bone each give rise to a distinct pattern of skeletal destruction, bone cancer-related pain behaviors and neurochemical changes in the central nervous system. Int. J. Cancer (2003) 104 550-558.

30 Watkins L.R., Hutchinson M.R., Rice K.C., Maier S.F. The "toll" of opioid-induced glial activation: improving the clinical efficacy of opioids by targeting glia. Trends Pharmacol. Sci. (2009) 30 581-591. 